\title{
The influence on carer wellbeing of motivations to care for older people and the relationship with the care recipient
}

\author{
CLARE LYONETTE* and LUGY YARDLEY*
}

\begin{abstract}
This paper reports an analysis of the relative influence of work-related, carerelated and personal factors on carer outcomes among 204 working female carers. To examine the importance of personal factors, the 'Motivations in Elder Care Scale' (MECS) and the 'Relationships in Elder Care Scale' (RECS) were developed. In a qualitative pilot study, interviews with working-age carers were drawn on to form the items for inclusion. The MECS included items for external pressures to care, e.g. guilt, the older person's expectation of care, and perceived disapproval of others, and for internal desires to adopt the caring role, e.g. carer's resistance to other forms of care, living up to one's principles and caring nature. Psychometric tests revealed that two subscales had greater reliability, the EXMECS (extrinsic motivations to care) and the INMECS (intrinsic motivations). The RECS included both positive items, e.g. respect, admiration for the older person, and lack of generational differences, and negative relationship items, e.g. struggle for power, and older person's resistance to caring efforts, and had good reliability. Measures of carer stress and carer satisfaction were included as outcome variables. Multiple regression analyses showed that the RECS and the MECS were the most significant predictors of carer outcomes. Greater extrinsic motivations to care and poorer quality of the relationship with the older person were the most significant predictors of carer stress. Better relationship quality and greater intrinsic motivations to care were the most significant predictors of carer satisfaction.
\end{abstract}

KEY WORDS - motivations, quality of relationship, older person caring, carer stress, carer satisfaction.

\section{Introduction}

There are currently over 5.7 million informal carers in the United Kingdom, with half of these caring for someone over the age of 75 years (Office of Population Censuses and Surveys i995). Although there are many male

* Department of Psychology, University of Southampton, UK. 
carers, 3.3 million are female, and of those carers devoting at least 20 hours a week to caring, over 6o per cent are women. It has been proposed that across Europe as a whole, there will be a $2 \mathrm{I} 3$ per cent increase in the population aged 80 or more years between ig8o and 2025 (Dooghe i992), and a similar rapid increase is expected in the United States (Kane and Penrod I995). The link between increased ageing and dependency means that the number of carers is also likely to rise (Henwood I992).

Research has shown that, while each caring situation is unique, certain factors are likely to contribute to the caring experience being perceived in a primarily positive or negative way by the female carer. Work-related factors that have been shown to influence the caring experience include whether the carer is in paid employment (Barnes, Given and Given I995; Dellasega I990; Hawkins I996; Orodenker ı99o; Stueve and O’Donnell I989), and the characteristics of this employment (Fredriksen and Scharlach I997; Martire, Stephens and Atienza I997). Care-related factors include the resident status of the older person, relationship to the older person, length of time since caring began, level of help given to the carer, and the level of carer assistance required (Gottlieb, Kelloway and Fraboni I994; Starrels et al. I997). A third set of factors has been shown to be important in the caring experience and these factors are referred to in this paper as 'personal'; they include inter-personal factors such as quality of the relationship with the older person (Lawrence, Tennstedt and Assmann I998; Pohl et al. i995; Townsend and Franks I995) and intra-personal factors such as motivations involved in older person care (Cicirelli I993; Finley, Roberts and Banahan i988).

Previous research has sometimes focused on the influence on carer outcomes of only one such factor, such as the personal aspects of caring (Horowitz and Shindelman I983) or the care-related aspects of caring (Starrels et al. I997). Other researchers have focused on the relative or combined influence of two of these factors on the overall caring experience, such as personal and care-related factors (Albert I992; Carruth I996; Cicirelli I993; Lawrence, Tennstedt and Assmann I998; Lyons et al. 2002 ; Peters-Davis, Moss and Pruchno ig99; Townsend and Franks I995; Yates, Tennstedt and Chang I999), or work-related and care-related factors (Fredriksen and Scharlach i997; Gottlieb, Kelloway and Fraboni I994; Martire, Stephens and Atienza I997; Murphy et al. I997; Scharlach, Sobel and Roberts I99I). To date, however, there has been very limited work on the relative or combined influence of all three of these factors on carer outcomes. In a Canadian qualitative study (Guberman and Maheu I999), it was found that several factors influenced women's attempts to combine work and employment, including work-related factors such as workplace conditions, personal factors such as motives for working and 
caring, and care-related factors such as the demands of caring for an older person. These factors in turn impacted upon older person caring and employment outcomes. This study demonstrated the importance of including many potentially influential variables when assessing the overall caring experience. The aim of the present study was therefore to examine the relationship between work-related, personal and care-related factors and their influence on carer wellbeing.

Previous researchers have used several measures when examining the influence of these factors upon the overall caring experience. When assessing work-related factors and their influence upon carer outcomes, most researchers have looked only at carer's employment status, rather than at the particular kinds of jobs undertaken by carers and how those jobs may influence the caring experience. Fredriksen and Scharlach (1997) showed however that job classification, work demand, workplace support and job flexibility contributed significantly to role strain among working carers at a university, demonstrating the relevance of specific work characteristics to the overall caring experience. Martire, Stephens and Atienza (I997) observed an important interaction between work-related and carerelated factors. Although satisfaction with both work and caring was positively related to greater wellbeing among carers, when higher levels of carer stress were recorded, high work satisfaction was associated with greater levels of depression. We therefore considered it desirable to include measures of specific job characteristics in the current research when examining the importance of work-related factors.

When assessing the influence of care-related factors on carer outcomes, previous research has shown that those carers who are co-resident with or live close to the older person experience greater carer stress (Goldsmith and Goldsmith 1995; Neal et al. 1993; Stoller and Pugliesi 1989), that longer duration of caring can lead to reduced carer strain (Mui and Morrow-Howell i993), that a closer kin relationship to the older person, such as spouse or parent, increases carer stress (Cantor 1983), and that emotional support mediates the effects of the need for care on carer overload and depression (Yates, Tennstedt and Chang 1999). Measures of all of these variables were therefore included in the present study. To assess the stress of caring, researchers have often employed measures of limitations in activities of daily living (ADLs) or instrumental activities of daily living (IADLs) in the older person. However, the evidence from previous research suggests that the decline in the older person's health is not a direct predictor of carer stress (George and Gwyther ig86; Miller I990). Measures of the older person's impairment may not relate closely to the perceived stress of caring, first because some carers may give only limited care despite severe impairment (e.g. if they are not the main carer), 
and secondly because of differences in the extent to which a given level of care is experienced as stressful. For these reasons, we chose to assess the experience of care as our dependent variable from the subjective perspective of the carer, using measures of carer stress and satisfaction.

Many previous researchers who have examined personal factors have selected only a specific aspect of relationship quality as the focus of their work, such as mutuality (Archbold et al. 1990), conflict and closeness (Townsend and Franks 1995), or sociability (Goldsmith and Goldsmith 1995). Other researchers have examined aspects of relationship quality among specific groups of carers, such as intimacy in mother-daughter relationships (Walker, Martin and Jones 1992), attachment and conflict in mother-daughter relationships (Pohl et al. 1995), differences in closeness of the relationship between wife and daughter carers (Seltzer and Wailing Li I996), or differences in relationship quality between co-resident daughters and daughters-in-law and older persons (Peters-Davis et al. 1999). Some have examined relationship quality using only single-item measures (Mui and Morrow-Howell i993), or Cantril ladders (Stoller and Pugliesi I989). Several studies used items from the 'Positive Affect Index' (Bengtson and Schrader 1982) to measure relationship quality in older person care relationships (Chang, Noonan and Tennstedt I998; Lawrence, Tennstedt and Assmann 1998; Seltzer and Wailing Li 1996; Yates, Tennstedt and Chang 1999). This, however, is a general measure of relationship quality, and was not designed specifically for older person care relationships.

None of the measures of the quality of the relationship with an older person used in previous research seemed entirely suitable for evaluating the overall quality of the relationship across diverse caring contexts. One consequence of the use of various limited measures of relationship quality is that while these have provided important evidence that the quality of a relationship is predictive of carer outcomes, the findings of different studies are difficult to compare. It was therefore decided that an inductive, interview-based approach would be used to develop a new measure which would apply to all types of relationships between informal carers and older care recipients, and which would examine more comprehensively the quality of those relationships. This approach has the advantage of allowing members of the population who are to be investigated to identify the factors that they consider most salient, and to describe them in detail in their own words. Clearly, such descriptions are unlikely to provide a complete and accurate analysis of all potentially relevant factors, since the interviewees may be unable or unwilling to report some influential factors. Nevertheless, the participants' accounts may provide rich detail of their perspectives, and these may complement insights from theory and expert knowledge. 
There appeared to be a similar need for a generic measure of motivations in older people's care. Some previous research has focused on particular motivations, such as filial obligation (Albert i992; Finley, Roberts and Banahan i988; Seelbach and Sauer 1977) and reciprocity (Carruth I996). Other studies have concentrated on motivations in specific older person care relationships, such as mother-daughter caring (Cicirelli i993), or on particular types of caring situations, such as dementia care (Carruth I996). While these studies have provided vital evidence that obligation, affection and reciprocity are important motivations in older person care, it is again difficult to compare the results of different studies. From a qualitative study, Guberman, Maheu and Maille (1992) reported that the main motivations for care (including care of adult children) encompassed love (including reciprocity), inadequate institutional or community resources, the profound need to help others, duty and obligation, the expectation of care, and women's socio-economic dependence. These findings suggest that previous quantitative studies may not have measured all relevant motivations. Consequently, it was decided to develop inductively a more comprehensive measure of motivations in older person care, for use with all carers of older people. In summary, the main objective of this study was to examine the influence of personal, work-related and care-related factors on carer outcomes. A prerequisite was to develop and validate two new measures, of relationships in older person care, and of motivations to care for an older person.

\section{Sample design, methods and instruments}

\section{Qualitative pilot stage}

A main objective of the pilot stage was to identify qualitatively the factors of greatest importance to female carers in managing work and caring responsibilities: these were to be included in the measures employed in the quantitative stage of the study. Interviews were held in the homes or workplaces of I4 female carers, I3 of whom were recruited through local carers' groups in southeast England, and one through an appeal in a university newsletter. All were of working age (under 65 years) and were caring for (or had until recently been caring for) an older person. The interviews, which lasted between one and two hours, were semi-structured and asked about how caring began, managing work and other responsibilities, and both positive and negative aspects of the overall caring experience.

All interviews were fully transcribed and coded, following the principles of thematic analysis (Boyatzis 1998). Common or similar themes were identified and 'key codes' agreed. As an example, concepts such as 'lack 
of choice', 'guilt' and 'perceived responsibility' were grouped with others to form the key 'motivations' code. Seven key codes were identified overall: the subjective experience of caring undertaken; work issues; support from family and friends; issues surrounding the provision versus the management of care; maintaining the self; the motivations for caring; and the quality of the relationship with the older person.

All the women focused on the subjective experience of caring and how this impacted on the other issues that they raised. An existing measure of the perceived stressfulness of different 'types of caring tasks undertaken' was therefore included in the main questionnaire study (Stephens, Franks and Atienza 1997). ${ }^{1}$ Work issues were investigated using previously validated measures of specific work characteristics, such as 'autonomy and control', 'work demands', 'peer support', 'work satisfaction' and 'work stress' (Haynes et al. 1999; Stephens, Franks and Atienza i997). The level of help with caring provided by family, friends and others was represented (Neal et al. 1993). Upon further examination, issues about the provision versus the management of care, and about maintaining the self, appeared to be relatively unimportant and were omitted from further quantitative analysis. There were two key codes for which no suitable existing measures could be found: motivations for caring, and the quality of the relationship with the older person. The interview data were therefore used to develop new measures of these factors for inclusion in the main questionnaire study.

\section{Participants and procedure}

A short screening survey was initially sent out to all 4,I42 female employees of two National Health Service hospitals in southeast England. Of these, 275 working carers expressed a willingness to respond to a further questionnaire on work and caring issues. The sample is therefore selfselected and cannot be considered representative of the wider carer population. Nevertheless, it was adequate for the development and validation of the new measures, and for determining whether they contributed to the understanding of the factors that influence the caring experience. All respondents were under 65 years of age, and had caring responsibilities for an older person. No restrictions were made about the carer's relationship with the older person, the number of hours of caring, or the older person's place of residence.

\section{Development of new measures}

Relationships in Elder Care Scale (RECS). Common themes, as identified from the interview transcripts, were used to form the pilot questions that were 
distributed to six carers or ex-carers. Four had already been interviewed and were still heavily involved in caring responsibilities, and two were excarers known to the researchers. The six participants suggested extra questions, which resulted in a total of $I 7$ items. As far as possible, the questions contained the interviewee's own wording, e.g. 'struggle for power'. The questions were designed to be unambiguous, and contained no directive or evaluative phrases. Some items were worded negatively and some positively to minimise response bias. Negative items were scored in the opposite direction from positive items, and all items were randomly ordered. A five-category Likert scale was used for responses, ranging from 'strongly agree' to 'strongly disagree'.

Turning to the Motivations in Elder Care Scale (MECS), as with the RECS, all 18 motivation items generated from the interviews were included as questions in the new scale. The wording of the questions was again where possible taken directly from the interview transcripts, and no directive language was used. The same five-point Likert scale was used, and the order of the questions was random.

\section{Other predictor measures}

Work characteristics. Following the work of Haynes et al. (I999), three measures of specific work characteristics were included: autonomy/control, work demands and peer support. These measures had been tested in a large study to examine the psychological wellbeing of National Health Service (NHS) employees, and exhibited satisfactory internal reliability. All the scales included also demonstrated good construct validity, and discriminated among the major NHS occupational groups and jobs: managers, doctors, nurses, professionals allied to medicine, professional and technical staff, and administrative staff. It was suggested that the scales might be less appropriate for ancillary staff, a group which was not included as a result of too few respondents.

Work satisfaction. This measure had been used in a United States study to assess positive and negative aspects of combining work and caring roles, and comprised eight items derived from a previous research study (Stephens, Franks and Atienza i997). The work stress scale was adopted from the same study. It comprised seven items from previous studies, and was designed for use alongside the measure of work satisfaction. Other questions were included to assess carers' marital status, self-reported health status, relationship to the older person, resident status of the older person, length of time since caring began, and help from family and friends. Age, occupation of the carers and hours worked were identified from the screening survey. 


\section{Outcome measures}

A 2I-item measure of carer stress, also from Stephens, Franks and Atienza (1997), was used to assess the amount of stress experienced by the carer in carrying out the caring tasks which they undertook. For carer satisfaction, the five item 'Caregiving appraisal' scale developed by Lawton et al. (I989) was included to assess the positive aspects of caring.

\section{Achieved sample and results}

\section{Sample characteristics}

Of the 275 questionnaires sent out, 204 questionnaires were returned and completed and have been used in the analysis, giving a 74 per cent response rate. ${ }^{2}$ The average age of the respondents was 49 years (standard deviation 7.2), while the average number of hours of NHS work was 29 hours per week (s.d. 9.6), reflecting a high representation of part-time employees. The average length of time since caring began was 5.8 years (s.d. 5.6), although some carers had been caring for much longer. The majority of respondents were nurses, although a few worked in more senior occupations such as doctors and managers (Table I). Most of the carers were married, and most described themselves as being in good or excellent health. The majority were caring either for a parent or a parent-in-law. Most of the older people whom they cared for lived in their own homes, although some lived in the carer's home or in a nursing home or care facility. Over half the respondents reported being either the main carer, with some help from others, or the only carer.

\section{Psychometric evaluation of the RECS and the MECS}

A reliability analysis was performed on the original i7 items of the RECS scale by calculating Cronbach's alpha for the scale as a whole, and then after each item had been deleted in turn. Five items (older person's changed character, change in the relationship, embarrassment over the older person's behaviour, sympathy for the older person and feeling protective towards the older person) detracted from the internal consistency of the scale and were removed. The final I2 items demonstrated good internal reliability (reliability statistics are presented in Table 2). The scale included both positive aspects of the relationship (such as respect, sympathy and admiration for the older person, as well as understanding of the older person), and negative aspects (such as frustration, conflict and the older person's resistance to the care provided). Follow-up analyses after one year revealed that the 12 items remained reliable over time. 
T A B L E I. Socio-demographic details of the main study sample

\begin{tabular}{|c|c|c|}
\hline Attribute & $\mathrm{N}$ & $\%$ \\
\hline \multicolumn{3}{|l|}{ Carer's occupation } \\
\hline Managers & I4 & 6.9 \\
\hline Doctors & 6 & 2.9 \\
\hline Nurses & III & $54 \cdot 4$ \\
\hline $\begin{array}{l}\text { Professionals allied to medicine/ } \\
\text { professional and technical staff }\end{array}$ & 33 & I6.2 \\
\hline Administrative staff & $4^{0}$ & I9.6 \\
\hline \multicolumn{3}{|l|}{ Carer's marital status } \\
\hline Single & I3 & 6.4 \\
\hline Married/living with a partner & I75 & 85.8 \\
\hline Divorced or separated & II & $5 \cdot 4$ \\
\hline Widowed & 3 & I. 5 \\
\hline \multicolumn{3}{|l|}{ Carer's health status } \\
\hline Poor or fair & 28 & I 3.7 \\
\hline Good or excellent & 172 & $84 \cdot 3$ \\
\hline \multicolumn{3}{|l|}{ Carer's relationship to the elder } \\
\hline Daughter & 122 & 59.8 \\
\hline Daughter-in-law & 32 & I5.7 \\
\hline Wife & 5 & 2.5 \\
\hline Sister or sister-in-law & o & o \\
\hline Friend or neighbour & 17 & 8.3 \\
\hline Other & I9 & $9 \cdot 3$ \\
\hline \multicolumn{3}{|l|}{ Elder's resident status } \\
\hline Lives in his/her own home & I54 & $75 \cdot 5$ \\
\hline Lives in carer's home & $2 \mathrm{I}$ & I0.3 \\
\hline Lives with a relative & 5 & 2.5 \\
\hline Lives with a friend & o & o \\
\hline Lives in a nursing home or care facility & $2 \mathrm{I}$ & 10.3 \\
\hline \multicolumn{3}{|l|}{ Help with caring } \\
\hline Only carer & 34 & I 6.7 \\
\hline Main carer, with some help & 74 & 36.3 \\
\hline Care shared equally with others & 64 & $3^{1} \cdot 4$ \\
\hline Some caring involvement & 29 & $\mathrm{I} 4.2$ \\
\hline Sample size & 204 & \\
\hline
\end{tabular}

When the same analysis was carried out for the MECS, a low Cronbach's alpha score (0.54) suggested that the scale was not a unitary measure. Factor analysis (principal components analysis with Varimax rotation) revealed six main factors with Eigen values of less than one, which together explained over 67 per cent of the variance. The first two factors explained substantial fractions of the variance $(26 \%$ and $14 \%$ respectively). The later factors explained much less, loaded on only a few items or input variables, and were difficult to interpret. Consequently, a two-factor solution principal components analysis was undertaken (see Table 3 for the factor loadings). 
T A в L E 2. Reliability statistics for the RECS and the MECS scales

\begin{tabular}{lccc}
\hline Variable & $\begin{array}{c}\text { Time I } \\
\text { Cronbach's alpha }\end{array}$ & $\begin{array}{c}\text { Time } 2 \\
\text { Cronbach's alpha }\end{array}$ & $\begin{array}{c}\text { Correlation of Time I } \\
\text { and Time 2 scores }\end{array}$ \\
\hline RECS & 0.87 & 0.85 & $0.74^{* * * *}$ \\
EXMECS & 0.84 & 0.83 & $0.77^{* * * *}$ \\
INMECS & 0.77 & 0.74 & $0.55^{* * *}$ \\
\hline
\end{tabular}

Significance level: *** $p \leqslant 0.001$.

T A в L E 3. Ranked factor loadings for the 13 items of the motivations in Elder Care Scale

\begin{tabular}{lcc}
\hline Items or variables & Factor I & Factor 2 \\
\hline No choice & 0.77 & -0.19 \\
Guilt & 0.75 & -0.20 \\
Elder's expectation & 0.75 & 0.05 \\
Perceived disapproval of others & 0.72 & 0.11 \\
Duty & 0.70 & -0.38 \\
Growing dependence of older person & 0.57 & -0.32 \\
Responsibility & 0.56 & -0.54 \\
Desire to care & 0.10 & 0.75 \\
Automatic decision to care & -0.05 & 0.72 \\
Carer's resistance to other forms of care & 0.04 & 0.67 \\
Living up to one's principles & -0.06 & 0.64 \\
To provide safety & -0.26 & 0.62 \\
Caring nature & -0.15 & 0.56
\end{tabular}

Notes: From a two factor solution of a Varimax rotation of a principal factor analysis. In rank order for Factor I and Factor 2.

Two sub-scales were then created from the items with loadings (correlation coefficients) greater than the modulus 0.5 on these factors. They were labelled 'Extrinsic motivations to care' (EXMECS) and 'Intrinsic motivations to care' (INMECS). The EXMECS comprised the first seven items in Table 3 (relating to feeling external pressures to adopt the caring role). It demonstrated good internal reliability at Times I and 2 (Table 2). The INMECS sub-scale comprised the remaining six items in Table 3 (relating to a personal desire to provide care) and also had satisfactory internal reliability over time. Pearson's product-moment correlations were carried out on scores obtained with the new measures at Time I and Time 2 (follow-up) in order to examine test-retest reliability. All scales showed good reliability (Table 2).

\section{Bivariate relationships}

Bivariate Pearson's product-moment correlations (for continuous variables) and analyses of variance (for categorical variables) were used to 
T А в L E 4. Correlation coefficients between personal variables and main outcome measures, carer stress and carer satisfaction

\begin{tabular}{lrccc}
\hline Variable & RECS & EXMECS & INMECS & $\begin{array}{c}\text { Carer } \\
\text { satisfaction }\end{array}$ \\
\hline EXMECS & $0.28^{* * *}$ & - & & \\
INMECS & $-0.2^{* * *}$ & $0.28^{* * *}$ & - & - \\
Carer satisfaction & $-0.63^{* * *}$ & $-0.18^{* *}$ & $0.47^{* * * *}$ & - \\
Carer stress & $0.49^{* * *}$ & $0.49^{* * *}$ & 0.09 & $-0.25^{* * *}$ \\
\hline
\end{tabular}

Notes: RECS: Relationships in Elder Care scale (higher scores=poorer quality of relationship). EXMECS: Extrinsic Motivations to Care scale (higher scores = higher extrinsic motivations to care). INMECS: Intrinsic Motivations to Care scale (higher scores $=$ higher intrinsic motivations).

Significance levels: * $p \leqslant 0.05,{ }^{* * *} p \leqslant 0.001$.

examine the relationships between each predictor variable and the outcome measures, carer stress and carer satisfaction. To reduce the possibility of a Type I error, ${ }^{3}$ only correlations with a level of significance of at least 0.005 are reported below as significant and were included in the regression analyses. Table 4 shows the results of tests of association between personal variables and the main outcome measures. Carer stress was positively associated with quality of relationship and extrinsic motivations to care, and negatively associated with carer satisfaction. In other words, those with a poorer quality of relationship and higher extrinsic motivations to care were more likely to report higher levels of carer stress. Similarly, those with a better quality of relationship and with greater intrinsic motivations to care were more likely to report higher levels of carer satisfaction. Better quality of relationship was related to greater intrinsic motivations and fewer extrinsic motivations. There was a significant, although not large, correlation between extrinsic and intrinsic motivations.

Table 5 shows the results of tests of association between work-related variables and carer outcomes. Carer satisfaction was positively correlated with peer support at work. Other work variables were not associated with carer satisfaction. There was a significant negative relationship between carer stress and work satisfaction, and a significant positive relationship between carer stress and work stress, as well as work demands. Higher work demands were negatively associated with work satisfaction and peer support, and positively associated with work stress. Peer support was positively associated with work satisfaction and negatively associated with work stress. Work stress and work satisfaction were significantly negatively associated.

Other tests of association were then carried out for caring variables and the main outcome measures. There was a significant association between resident status of the older person and carer stress, with those caring for a 
T A B L E 5. Correlation coefficients between work-related variables and main outcome measures, carer stress and carer satisfaction

\begin{tabular}{lcccccc}
\hline Variable & Autonomy & $\begin{array}{c}\text { Work } \\
\text { demand }\end{array}$ & $\begin{array}{c}\text { Peer } \\
\text { support }\end{array}$ & $\begin{array}{c}\text { Work } \\
\text { satisfaction }\end{array}$ & $\begin{array}{c}\text { Work } \\
\text { stress }\end{array}$ & $\begin{array}{c}\text { Carer } \\
\text { stress }\end{array}$ \\
\hline Work demand & $0.19^{*}$ & - & & & & \\
Peer support & $0.14^{*}$ & $-0.20^{*}$ & - & & & \\
Work satisfaction & $0.16^{*}$ & $-0.48^{* * *}$ & $0.43^{* * *}$ & - & & \\
Work stress & -0.05 & $0.64^{* * *}$ & $-0.25^{* *}$ & $-0.58^{* * *}$ & - & \\
Carer stress & 0.05 & $0.21^{* *}$ & $-0.19^{*}$ & $-0.27^{* * *}$ & $0.21^{* *}$ & - \\
Carer satisfaction & 0.00 & 0.04 & $0.27^{* * *}$ & 0.10 & -0.05 & $-0.25^{* * *}$ \\
\hline
\end{tabular}

Significance levels: $* p \leqslant 0.05,{ }^{* *} p \leqslant 0.005,{ }^{* * *} p \leqslant 0.00 \mathrm{I}$

co-resident older person recording significantly higher levels of stress than all other groups $(\mathrm{F}=7 . \mathrm{II} ; \mathrm{df}=3 ; p<0.00 \mathrm{I})$. However, as there were only 2I carers co-resident with the older person, these results must be treated with caution. There were no significant associations between caring outcomes and any of the other caring variables included, although there was a tendency for daughters-in-law to record higher stress scores than those caring for a neighbour or friend, or an 'other' (unspecified caring relationship group). Those caring for a parent also recorded significantly higher extrinsic motivation scores than those caring for a friend or neighbour $(\mathrm{F}=4.63 ; \mathrm{df}=4 ; p<0.005)$. There was also a tendency for those caring for a parent-in-law to record higher extrinsic motivations than those caring for a friend or neighbour. In each of these cases, however, the low number of carers in the comparison group reduces the reliability of the findings. Those receiving the most help with caring also recorded significantly lower extrinsic motivations to care than those caring alone or with a minimum of help ( $\mathrm{F}=\mathrm{II} .77 ; \mathrm{df}=3 ; p<0.00 \mathrm{I})$, although again, there were small numbers in each of the groups. There were no significant associations between carer outcomes and marital status, carer's health status, age of the carer, occupation or hours worked.

\section{Regression analyses}

Stepwise regression analyses were then carried out to identify the combinations of variables predictive of carer outcomes. All variables significantly correlated with carer stress and carer satisfaction were entered. Resident status was not included in the regression analysis due to the low numbers in the co-resident group. Extrinsic motivations to care (EXMECS) and quality of relationship with the older person (RECS) were the most significant independent predictors of carer stress (Table 6). Lower work satisfaction also contributed to carer stress, to a lesser degree, but after controlling for these variables, work demands no longer explained any 
T A B L E 6. Stepwise regression models of carer stress and carer satisfaction for working carers

\begin{tabular}{lccccc}
\hline Step & Predictor variables & Beta & Change in $\mathrm{R}^{2}$ & $\mathrm{~F}$ & $\begin{array}{c}\text { Significance } \\
\text { of } \mathrm{F}\end{array}$ \\
\hline Carer stress & & & & \\
I & Extrinsic motivations & $0.39^{* * *}$ & 0.24 & 57.34 & $<$ o. ooI \\
2 & Relationship quality & $0.34^{* * *}$ & 0.14 & 54.23 & $<$ o.ooI \\
3 & Work satisfaction & $-0.13^{*}$ & 0.02 & 38.39 & $<$ o.ooI \\
Carer satisfaction & & & & \\
I & Relationship quality & $-0.54^{* * * *}$ & 0.40 & 126.64 & $<$ o.ooI \\
2 & Intrinsic motivations & $0.30^{* * *}$ & 0.08 & 85.68 & $<$ o.ooI \\
\hline
\end{tabular}

Notes: Variables entered into the two regression analyses: (a) Carer stress: RECS, EXMECS, work satisfaction, work stress, work demand. (b) Carer satisfaction: RECS, INMECS, peer support.

Significance levels: $* p \leqslant 0.05,{ }^{* * *} p \leqslant 0.001$.

further variance in carer stress. These three independent variables therefore accounted for almost $3^{8}$ per cent of the variance in carer stress. For carer satisfaction, quality of relationship with the older person (RECS) and intrinsic motivations to care (INMECS) were the most significant independent predictors; after controlling for these variables, peer support did not contribute significantly to satisfaction. Taken together, these two variables therefore accounted for over 47 per cent of the variance in carer satisfaction for this group of working carers.

\section{Discussion}

The main objective of the study was to examine the influence of personal factors on the subjective experience of caring, relative to and in combination with work-related and care-related factors. The principal finding is that greater extrinsic motivations to care and poorer quality of the relationship with the older person, as measured by the two new scales developed for the study, were the most significant predictors of carer stress in a sample of female carers, taking precedence over care-related and workrelated factors. These results suggest that many working carers take on caring for an older person as a result of feelings of guilt, duty, responsibility and lack of choice, associated with the growing dependence of the older person, the older person's expectation of care and the perceived disapproval of others if they do not take on the care. The perception of such external pressures to care is in turn associated with increased levels of carer stress. These findings are consistent with those of Cicirelli (1993), who found that a sense of obligation was positively associated with greater burden in daughter-carers. 
In our study, increased carer stress was also independently associated with a poor relationship with the older person, including feelings of frustration linked with perceptions of the older person as negative, stubborn, changed, resistant to the carer's efforts, and engaged in a power struggle with the carer. Many previous researchers have shown that aspects of the care relationship can be associated with negative outcomes (Archbold et al. I990; Lyons et al. 2002; Walker, Martin and Jones 1992). The research reported here extends these findings by including aspects of the quality of the care relationship, such as the struggle for power and the older person's resistance to caring efforts, and by demonstrating the importance of the carer-older person relationship across many caring situations.

For carer satisfaction, better relationship quality and greater intrinsic motivations to care were the most significant predictors. Those working carers reporting respect and admiration for the older person, higher quality of past and current relationship, as well as the older person's understanding, lack of generational differences and fewer money issues, also reported greater carer satisfaction. These findings support earlier work on positive aspects of the care relationship and their influence on carer outcomes (Cicirelli 1993; Pohl et al. 1995; Stoller and Pugliesi 1989). However, Cicirelli (I993) and Pohl et al. (I995) examined only the quality of relationship in mother-daughter caring. The results reported here suggest that the quality of a relationship in diverse older person care situations predicts the level of carer satisfaction. Women who were more satisfied with the caring role described themselves as 'natural' carers who wanted to care for the older person, made an automatic decision to do so, were resistant to alternative forms of care, wanted to provide safety for the older person, and saw caring as a way of living up to their principles. Again, a combination of personal factors was shown to be more predictive of carer satisfaction than either work-related or care-related factors for this group of working female carers. Guberman, Maheu and Maille (1992) earlier identified some of the motivations outlined above in their qualitative study of female carers, but the study reported here expands on this research by also measuring the predictive value of such motivations on carer outcomes.

The resident status of the older person was also associated with carer stress, with those caring for a co-resident recording significantly higher levels of stress. Because of the small number of carers in the co-resident group, this variable was not included in the regression analysis, although results support previous research showing that those carers who are coresident or who live close to the older person experience greater stress (Goldsmith and Goldsmith 1995; Neal et al. 1993; Stoller and Pugliesi I989). Lower satisfaction with work was also linked with increased carer stress, but to a lesser degree than motivations and relationship quality, and 
after these variables had been taken into account the work-related variables we measured were unrelated to carer satisfaction. Martire, Stephens and Atienza (1997) found that women who were more satisfied at work experienced fewer depressive symptoms than women who were less satisfied, but they also found that, with high carer stress, work satisfaction was associated with greater depression. It may be that factors such as work satisfaction contribute to negative outcomes, but only become problematic with high extrinsic motivations and a poor quality of relationship with the older person.

While these findings provide indications of the potential role of personal factors in the caring experience, they cannot be generalised to the whole carer population because the sample was self-selected and all worked in health care. The age distribution is however comparable with those in other carer research samples (Gorey, Rice and Brice 1992; Franklin, Ames and King 1994; Stephens and Franks 1995; Martire, Stephens and Atienza 1997; Starrels et al. 1997; Rands 1997; Penning 1998). Arber and Ginn (I99I) also suggested that over three-quarters of the care provided to the over-65s in Britain was given by people aged over 45 years, a share consistent with the current data.

Other similarities with earlier samples were revealed, as in marital status and carer's health status (Gottlieb, Kelloway and Fraboni i994; Penning 1998). Many in the present sample worked part-time. Rands (1997) also reported that carers were likely to be in part-time work, but a study using British Household Panel Study data reported that the average number of hours worked by informal carers was 33.2 (Hutton I999). The average length of time since caring began was also consistent with earlier studies (Gorey, Rice and Brice 1992; Stephens and Franks 1995; Martire, Stephens and Atienza 1997). The majority of the respondents were caring for either a parent or a parent-in-law, as is usually found. A meta-analysis of $\mathrm{I} 7$ independent US studies reported that 74 per cent of carers cared for a parent or a parent-in-law (Gorey, Rice and Brice I992).

Most of the older care recipients lived in their own homes, although some lived in the carer's home or in a nursing home or care facility. Although the Office of Population Censuses and Surveys carer survey data showed that 20 per cent of male and female carers in the United Kingdom were co-resident with the older person, Laczko and Noden (I992) pointed out that 40 per cent of these were spouses and therefore likely to be old themselves. From a large United States employee survey, Starrels et al. (1997) found only io per cent of carers to be co-resident with the older person, as in the present study. Over half the respondents in the present study reported being either the main carer, with some help from others, or the only carer, as consistent with other samples (e.g. Penning I998; Rands I997). 
The second objective of this study was to develop and validate new measures of two personal factors in the caring experience, the quality of the relationship and motivations to care for an older person. The qualitative pilot stage identified several previously unmeasured aspects of both relationship quality and motivations. As mentioned earlier, the new items generated, using this inductive approach, are consistent with the findings of the qualitative study by Guberman, Maheu and Maille (1992), although that study included motivations to care for adult children, which naturally differed from the motivations of interest here. The new scales, the RECS and the two subscales of the MECS, measure relationship quality and motivations in all kinds of older person care relationships and caring situations, and so facilitate comparisons across different studies. After psychometric testing and revision of the items, both the RECS and the two MECS subscales demonstrated good reliability and validity, and follow-up analysis after one year revealed that they remained stable over time.

Although there was a tendency for women caring for a parent-in-law to record higher carer stress scores than those caring for a friend, neighbour or 'other' (unspecified relationship) person, this association was not significant at the 0.005 level, and the low number of carers in the comparison group did not permit firm conclusions. Previous research demonstrated however that a close kin relationship, such as spouse or parent, led to increased carer stress (Cantor I983). This study's sample comprised women from several different occupational backgrounds, including managerial and administrative staff and health care workers. A large number of the respondents were nurses, many of whom worked part time, and further research is needed to determine whether the personal factors measured by the two new scales predict carer outcomes in other female working carers. It could be that among women working full-time and in non-care-related occupations, work-related factors are more important predictors of carer outcomes. The sample was also self-selected: those with more trying care situations may have felt unable to participate through time pressures, or alternatively, they may have been more willing to respond as a result of their interest in the subject. This possibility has been noted in a study of working carers (Martire, Stephens and Atienza 1997).

Although it has been demonstrated that personal factors were the greatest predictors of both carer stress and carer satisfaction, it was not possible to determine the direction of the effect. Carers who report high carer stress may be likely to report a poor quality of relationship as a consequence of stress, rather than because the poor quality of relationship caused their stress. Indeed, there is the possibility that two-way effects characterise all the relationships studied in this analysis. 
It appears from the results presented here that perceived relationship difficulties arise largely as a consequence of resistance to the interdependence of the carer and the older person, and that relationship problems are therefore linked to the motivations involved in caring. This interpretation is supported by the highly significant associations between quality of relationship and both extrinsic and intrinsic motivations to care. McKee (2002) noted that disagreement between the carer and the older person over the level of dependence was associated with several variables, including the care relationship, and predicted outcomes such as worsening carer stress. A recent United States study reported that the relationship strain perceived by the carer (but not by the older person) was significantly associated with disagreement between the carer and the older person over caring difficulties (Lyons et al. 2002). By analysing the discourse of carers and care recipients about relationship difficulties, Forbat (2002) noted that such difficulties were often used to justify problems in the current care relationship, and that the carer identity was often rejected by either the older person or the carer herself.

In this study, the carers who received most help with caring recorded comparatively few extrinsic motivations to care, one of the main predictors of carer stress. As mentioned earlier, two-way relationships could exist, so that high carer stress could feed back into a greater perception of external pressures to care and poor relationship quality, creating a cycle of resentment in the carer role. In the same way, higher carer satisfaction could feed back into greater perceptions of intrinsic motivations to care and better quality of relationship, leading to a positive cycle of caring.

If further research with different samples of working carers confirmed these findings, policy makers should address the influence of personal factors on carer wellbeing. Whereas it is not possible for policy makers to implement change in some aspects of the caring experience, such as the carer's kin relationship to the older person, by directing help specifically to those women who report relationship difficulties and external pressures to care, it may be possible to ameliorate some negative aspects of the caring experience, and thereby break the cycle of resentment in the carer role, relationship difficulties and stress.

\section{Acknowledgements}

This research was supported, in part, by funding from the Economic and Social Research Council. The authors wish to express thanks to Dr Bob Stratford at the University of Southampton for helpful comments and support throughout the research. 


\section{NOTES}

I For copies of the questionnaire and coding details, please contact the corresponding author.

2 Of the distributed questionnaires, I4 were returned incomplete, one carer had left work to care, one was caring for a child rather than an older person, and one questionnaire was returned to sender. Another seven carers returned the questionnaire, and reported that the older person had recently died. All of these respondents were excluded from the data analysis.

3 Rejection of a null hypothesis when it is true. The likelihood is increased when multiple tests are carried out.

\section{References}

Albert, S. M. 1992. Psychometric investigation of a belief system: caregiving to the chronically ill parent. Social Science and Medicine, 35, 5, 699-709.

Arber, S. and Ginn, J. I99. Gender and Later Life. Sage, London.

Archbold, P. G., Stewart, B. J., Greenlick, M. R. and Harvath, T. A. I99o. Mutuality and preparedness as predictors of caregiver role strain. Research in Nursing and Health, I2, $375^{-84}$.

Barnes, C. L., Given, B. A. and Given, C. W. 1995. Parent caregivers: a comparison of employed and not employed daughters. Social Work, 4o, 3, 375-8I.

Bengtson, V. L. and Schrader, S. S. I982. Parent-child relations. In Mangen, D. J. and Peterson, W. A. (eds), Social Roles and Social Participation. University of Minneapolis Press, Minneapolis, Minnesota, I54.

Boyatzis, R. E. I998. Transforming Qualitative Information: Thematic Analysis and Code Development. Sage, London.

Cantor, M. H. 1983. Strain among caregivers: a study of experience in the United States. The Gerontologist, 23, 6, 597-6o4.

Carruth, A. K. I996. Motivating factors, exchange patterns, and reciprocity among caregivers of parents with and without dementia. Research in Nursing and Health, r 9, 409-I9.

Chang, B. H., Noonan, A. E. and Tennstedt, S. L. I998. The role of religion/spirituality in coping with caregiving for disabled elders. The Gerontologist, 38, 4, 463-70.

Cicirelli, V. G. 1993. Attachment and obligation as daughters' motives for caregiving behaviour and subsequent effect on subjective burden. Psychology and Aging, 8, 2, I44-55.

Dellasega, C. I990. The relationship between caregiving and employment: a study of stress in employed and unemployed caregivers of elderly persons. AAOHN Fournal, 38, 4 , I54-9.

Dooghe, G. I992. Informal caregiving of elderly people: a European review. Ageing and Society, 1 2, 369-80.

Finley, N. J., Roberts, M. D. and Banahan, B. F. I988. Motivators and inhibitors of attitudes of filial obligation toward aging parents. The Gerontologist, 28, I, 73-8.

Forbat, L. 2002. Caregiving relationships: two sides to the story. Proceedings of the British Psychological Society conference. Blackpool, March 2002.

Franklin, S. T., Ames, B. D. and King, S. i994. Acquiring the family eldercare role: influence on female employment adaptation. Research on Aging, I6, I, 27-42.

Fredriksen, K. I. and Scharlach, A. E. I997. Caregiving and employment: the impact of workplace characteristics on role strain. Fournal of Gerontological Social Work, 28, 4, 3-22.

George, L. K. and Gwyther, L. P. I986. Caregiver well-being: a multidimensional examination of family caregivers of demented adults. The Gerontologist, 26, 253-9. 
Goldsmith, E. B. and Goldsmith, R. E. 1995. Full-time employees as caregivers to the elderly. Fournal of Social Behaviour and Personality, ro, 3, 719-30.

Gorey, K. M., Rice, R. W. and Brice, G. C. I992. The prevalence of elder care responsibilities among the work force population: response bias among a group of cross-sectional surveys. Research on Aging, I4, 3, 399-418.

Gottlieb, B. H., Kelloway, E. K. and Fraboni, M. 1994. Aspects of eldercare that place employees at risk. The Gerontologist, 34, 6, 815-21.

Guberman, N. and Maheu, P. I999. Combining employment and caregiving: an intricate juggling act. Canadian Fournal on Aging, I 8, I, 84-106.

Guberman, N., Maheu, P. and Maille, C. I992. Women as family caregivers: why do they care? The Gerontologist, 32, 5, 607-17.

Hawkins, B. 1996. Daughters and caregiving: taking care of our own. AAOHN Journal, 44, 9, 433-7.

Haynes, C. E., Wall, T. D., Bolden, R. I. and Stride, C. I999. Measures of perceived work characteristics for health services research: test of a measurement model and normative data. British Fournal of Health Psychology, 4, 257-75.

Henwood, M. I992. Through a Looking Glass Darkly: Community Care and Elderly People. King's Fund Institute, London.

Horowitz, A. and Shindelman, L. W. I983. Reciprocity and affection: past influences on current caregiving. Fournal of Gerontological Social Work, 5, 3, 5-20.

Hutton, S. 1999. The Employment of Those Undertaking Informal Care: A Longitudinal Analysis. Social Policy Research Unit, University of York, York.

Kane, R. A. and Penrod, J. D. 1995. Family Caregiving in an Aging Society: Policy Perspectives. Sage, Thousand Oaks, California.

Laczko, F. and Noden, S. 1992. Combining paid work with eldercare: the implications for social policy. Health and Social Care, I, 8I-9.

Lawrence, R. H., Tennstedt, S. L. and Assmann, S. F. I998. Quality of the caregiver-care recipient relationship: does it offset negative consequences of caregiving for family caregivers? Psychology and Aging, I3, I, I50-8.

Lawton, M. P., Kleban, M. H., Moss, M., Rovine, M. and Glicksman, A. I989. Measuring caregiving appraisal. Fournal of Gerontology: Psychological Sciences, 44, 3, 6I-7I.

Lyons, K. S., Zarit, S. H., Sayer, A. G. and Whitlatch, C. J. 2002. Caregiving as a dyadic process: perspectives from caregiver and receiver. Fournal of Gerontology: Psychological Sciences, $\mathbf{5 7}^{\mathbf{B}}, 3$, I95-204.

McKee, K. J. 2002. Outcomes of disagreement between carer and care-receiver over activities of daily living. Proceedings of the British Psychological Society conference. Blackpool, Lancashire, March 2002.

Martire, L. M., Stephens, M. A. P. and Atienza, A. A. 1997. The interplay of work and caregiving: relationships between role satisfaction, role involvement, and caregivers' well-being. Fournal of Gerontology: Social Sciences, 52B, 5, S279-89.

Miller, B. I99o. Gender differences in spouse caregiver strain: socialization and role expectations. Fournal of Marriage and the Family, 52, 31 I-2I.

Mui, A. C. and Morrow-Howell, N. 1993. Sources of emotional strain among the oldest caregivers. Research on Aging, I 5, I, 50-69.

Murphy, B., Schofield, H., Nankervis, J., Bloch, S., Herrman, H. and Singh, B. 1997. Women with multiple roles: the emotional impact of caring for ageing parents. Ageing and Society, I 7, 277-9I.

Neal, M. B., Chapman, N. J., Ingersoll-Dayton, B. and Emlen, A. C. I993. Balancing Work and Caregiving for Children, Adults and Elders. Family Caregiver Application Series, Volume 3. Sage, Newbury Park, California.

Office of Population Censuses and Surveys 1995. General Household Survey. Her Majesty's Stationery Office, London. 
Orodenker, S. Z. I990. Family caregiving in a changing society: the effects of employment on caregiver stress. Family Community Health, 1 2, 4, 58-70.

Penning, M. J. 1998. In the middle: parental caregiving in the context of other roles. Fournal of Gerontology: Social Sciences, 53B, 4, Si88-97.

Peters-Davis, N. D., Moss, M. S. and Pruchno, R. A. 1999. Children-in-law in caregiving families. The Gerontologist, 39, I, 66-75.

Pohl, J. M., Boyd, C., Liang, J. and Given, C. W. 1995. Analysis of the impact of motherdaughter relationships on the commitment to caregiving. Nursing Research, 44, 2, 68-75.

Rands, G. I997. Working people who also care for the elderly. International fournal of Geriatric Psychiatry, 1 2, 39-44.

Scharlach, A. E., Sobel, E. L. and Roberts, R. E. L. I991. Employment and caregiver strain: an integrative model. The Gerontologist, 31, 6, 778-87.

Seelbach, W. G. and Sauer, W.J. I977. Filial responsibility expectations and morale among aged parents. The Gerontologist, I 7, 6, 492-9.

Seltzer, M. M. and Wailing Li, L. I996. The transitions of caregiving: subjective and objective definitions. The Gerontologist, 36, 5, 6 $\mathrm{I}_{4}-26$.

Starrels, M. E., Ingersoll-Dayton, B., Dowler, D. W. and Neal, M. B. I997. The stress of caring for a parent: effects of the elder's impairment on an employed, adult child. Fournal of Marriage and the Family, 59 (November), 86o-72.

Stephens, M. A. P. and Franks, M. M. 1995. Spillover between daughters' roles as caregiver and wife: interference or enhancement? Fournal of Gerontology: Psychological Sciences, 5oB, I, $\mathrm{P}_{9-17}$.

Stephens, M. A. P., Franks, M. M. and Atienza, A. A. i997. Where two roles intersect: spillover between parent care and employment. Psychology and Aging, 1 2, I, 30-7.

Stoller, E. P. and Pugliesi, K. L. I989. Other roles of caregivers: competing responsibilities or supportive resources? Fournal of Gerontology: Social Sciences, 44, 6, S23 I-8.

Stueve, A. and O'Donnell, L. I989. Interactions between women and their elderly parents: constraints of daughters' employment. Research on Aging, I I , 3, 35 I-3.

Townsend, A. L. and Franks, M. M. I995. Binding ties: closeness and conflict in adult children's caregiving relationships. Psychology and Aging, 10, 3, 343-51.

Walker, A. J., Martin, S. S. K. and Jones, L. L. I992. The benefits and costs of caregiving and care receiving for daughters and mothers. Fournal of Gerontology: Social Sciences, 47, 3, Sizo-9.

Yates, M. E., Tennstedt, S. and Chang, B. H. I999. Contributors to and mediators of psychological well-being for informal caregivers. Fournal of Gerontology: Psychological Sciences, 54B, I, P12-22.

Address for correspondence:

Accepted 25 February 2003

Lucy Yardley, Department of Psychology, University of Southampton, Southampton SOr7 iBJ, UK.

e-mail: L.Yardley@soton.ac.uk 